\begin{tabular}{|c|c|c|}
\hline $\begin{array}{l}\text { EXCELLENT } \\
\text { PUBLISHERS } \\
\end{array}$ & 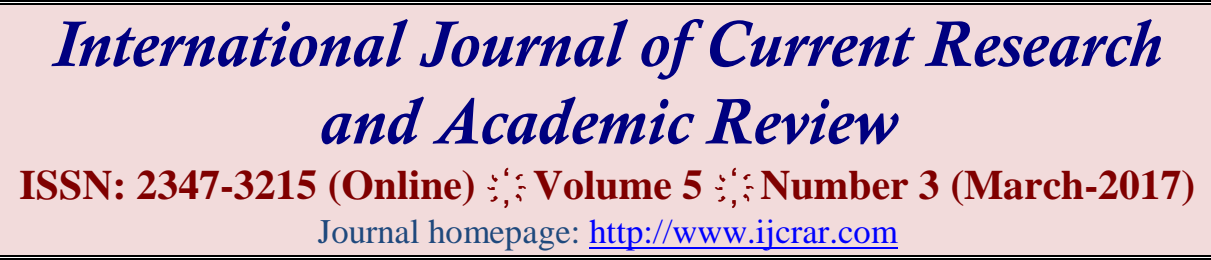 & 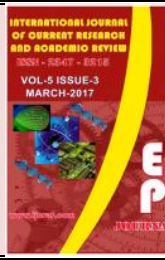 \\
\hline
\end{tabular}

doi: $\underline{\text { https://doi.org/10.20546/ijcrar.2017.503.006 }}$

\title{
An Inter-Temporal Analysis on the Performance of Select Mutual Funds in India
}

\author{
A. Meenakshi ${ }^{1}$ and Ti. M. Swaaminathan ${ }^{2 *}$
}

\begin{abstract}
${ }^{1}$ Ph.D (Part- Time) Research Scholar and Assistant Professor in Commerce, Pachaiyappa's College for Women, Kanchipuram-631501, India

${ }^{2}$ Associate Professor and Head, PG and Research Department of Commerce, Pachaiyappa's College for Men, Kancheepuram - 631 501, India

*Corresponding author
\end{abstract}

\begin{abstract}
A Development of capital market in a country is an important business growth and thereby contributing towards economic development. The rises in savings and the consequent increase in the investment in financial assets argue well for the growth of capital market. Thus it necessitates studying the saving and investment in capital market in general and mutual fund is an investment option in particular among various avenues. The investment should always have an objective such as to have a regular income, to add to asset, wealth and to save taxes etc. Mutual funds pool the resources of small investors together, increasing their participation in financial markets. Second, mutual funds, being institutional investors, can invest in market analysis generally not available or accessible to individual investors. Decisions made on the basis of deeper understanding of risks and returns contribute to financial stability, besides helping to mitigate market risk for this group of investors. Third, transparency in investment strategies and outcome is relatively easy to deliver on. This study deals with the systematic and unique risks and returns of the selected schemes in terms of Sensex and Nifty in India.
\end{abstract}

\section{Article Info}

Accepted: 28 February 2017

Available Online: 20 March 2017

\section{Keywords}

Mutual Funds, Inter-Temporal Analysis.

\section{Introduction}

Financial system in India comprises of financial institutions, financial markets, financial instruments and services. Financial market refers to those places where financial assets are created and traded. The Reserve Bank of India (RBI) as the main regulator of credit is the apex institution in the financial system. Other important financial institutions are the commercial banks (in the public and private sector), cooperative banks, regional rural banks and development banks. Non-bank financial institutions include finance and leasing companies and other institutions like Life Insurance Corporation (LIC) of India, General Insurance Corporation (GIC), Unit Trust of India (UTI), Mutual funds, Provident Funds, Post Office, Banks etc. Financial markets are mainly classified as Money Market and Capital Market.

\section{Mutual funds}

Mutual funds are essentially investment vehicles where people with similar investment objective come together to pool their money and then invest accordingly. Each unit of any scheme represents the proportion of pool 
owned by the unit holder (investor). Appreciation or reduction in value of investments is reflected in net asset value (NAV) of the concerned scheme, which is declared by the fund from time to time. Mutual fund schemes are managed by respective Asset Management Companies (AMC). Different business groups / financial institutions / banks have sponsored these AMCs, either alone or in collaboration with reputed international firms.

\section{Performance evaluation of mutual funds}

The main idea in most of the classical measures of investment performance is quite simple. The measures essentially compare the return of a managed portfolio over some evaluation period to the return of a benchmark portfolio. The benchmark portfolio should represent a feasible investment alternative to the managed portfolio being evaluated. If the objective is to evaluate the investment ability of the portfolio manager or management company, as has typically been the case, the benchmark should represent an investment alternative that is equivalent, in all return-relevant aspects, to the managed portfolio being evaluated, except that it should not reflect the investment ability of the manager.

Historically, the earliest asset pricing models made relatively simple predictions about what it means for a benchmark is to a managed portfolio. The Capital Asset Pricing Model (CAPM) of Sharpe (Sharpe, 1966) implies that all investors should hold a broadly diversified "market portfolio," combined with safe assets or "cash," according to the investor's tastes for risk. It follows that the benchmark portfolio is a broadly diversified portfolio, combined with safe assets or cash, mixed to have the same market risk exposure, or "beta" coefficient as the fund. This is the logic of Jensen's (1968) alpha, which remains one of the most widely used measures of risk-adjusted performance. If alpha is positive the manager earns an abnormal return relative to the alternative of holding the benchmark portfolio strategy (Aragon and Ferson, 2006).

In performance assessment, not only the extent of diversification, but also the quality of diversification needs to be analysed, which depends upon the nature of stocks that are added to the portfolio. Only by identifying the correct stocks, can the fund manager reduce the risk and / or increase return. This is indicated as the efficiency of fund managers in stock selection. This is termed as differential return by Sharpe, under his Differential Return Model (Sharpe, 1975). This differential return is the risk adjusted return, net of riskfree return and systematic risk measures of return.

The risk adjusted performance measures analysed the overall performance of the sample funds. However, it is required to breakdown the performance into different components, which was done by Fama (1972). According to Fama, portfolio return consists of four components viz., risk-free return, compensation for systematic risk (beta impact), compensation for inadequate diversification (diversification impact) and net superior returns due to selectivity (selectivity impact).

Similarly, formal models of market timing ability were first developed in the 1980s, following the intuitive regression model of Treynor and Mazuy (1966). In the simplest example, a market timer has the ability to change the market exposure of the portfolio in anticipation of moves in the stock market. Before the market goes up, the timer takes on more market exposure and generates exaggerated returns. Before the market goes down, the timer moves into safe assets and minimizes losses.

\section{Problem of the study}

Mutual funds are the offshoot of capital market, where even small investors are encouraged to enter and earn more than what the conventional investment instruments like bank/post office deposits, provident funds and others can provide. Even though this underscores the presence of greater risk than the conventional products nonetheless, it is less than the risk involved in the equity market. Unlike the capital market or equity market in particular, mutual fund investment is absolutely guided by a professional investment manager, who acts on behalf of the individual investor. This implies the fact that the risk exposed or the return earned by the investor is influenced by various factors which include the personal whims and fancies of the investment manager and also the equity market, money market and others.

Competition among the AMCs in attracting individual investors has not only made the former to come out with different types of funds, but also to invest aggressively to earn greater return. In most of the cases, the individual investor may not be aware about the level of risk he is exposed to or the actual areas in which his money is invested by the AMC. While the risk quotient is higher in the equity market, even the Government security market has been fluctuating due to liberalisation. Thus, income 
earned by the investor from his mutual fund investment may not be fixed or may not actually match his expectation. In this background, it is quite important to evaluate the performance of different types of mutual funds which are offered by different AMCs, which is attempted in this study.

\section{Significance of the study}

The mutual fund industry has grown over the years, from only one AMC in the beginning to 43 currently. The investors can only choose the type of scheme in which their money needs to be invested by the AMC and they may not know the actual company or instrument in which his money is invested. Moreover, many external factors also simultaneously influence the level of return earned from mutual funds, which include the changes in the equity market, money market, Government policies regarding industries, foreign institutional investment, changes in the domestic economy, other economies, etc. Also, the globalised economy has made greater volatility a rule rather than an exception. Hence, the individual investor do not know when to invest, where to invest, how much to invest, and more importantly, the level of risk and return he is exposed to. This calls for a thorough analysis about the performance of the mutual funds in India, which is done in this study. While similar attempts have been made in the past, this study deviates from them by: a) considering all major types of schemes, viz., growth, income, balanced, tax saving, gilt, liquid and fund of funds; b) taking a five year period, from 2011-12 to $2015-16$, which is the crucial period in the mutual fund industry as it has seen many mergers and acquisitions; c) considering 150 schemes from both public and private sector; and d) comparing the returns from the schemes vis-a-vis two benchmarks, viz., Sensex and Nifty.

\section{Period of the study}

This study examines the performance of the select mutual funds for a five year period, 2011-12 to 2015-16, since during this period, the mutual fund industry has undergone many changes in the form of mergers and acquisitions. Moreover, the stock market too has witnessed marked fluctuations in this period.

\section{Objectives of the study}

The major objective of the study is:

To evaluate the performance of select mutual funds in India
This objective has been narrowed down into the following specific objectives:

1. To study the systematic and unique returns of the selected schemes in terms of Sensex and Nifty;

2. To study the systematic and unique risks and returns of the selected schemes in terms of Sensex and Nifty;

\section{Hypotheses of the study}

Based on the objectives, the following hypotheses are framed:

1. There is no significant difference in the risk between the public and private sectors' sample schemes;

2. There is no significant association between risk and returns of the sample schemes during the study period;

\section{Methodology of the study}

This study evaluates the performance of the selected mutual fund schemes for a five year period, 2011-12 to 2015-16. For this purpose, the NAVs of the sample schemes have been gathered from the official websites of the respective AMCs or from that of Association of Mutual Funds in India (AMFI). The risk and return of the sample schemes have been evaluated with the application of standard deviation, Internal Rate of Return (IRR), systematic risk and unique risk. Also, in order to understand the extent of risk and return of the sample schemes, the same has been compared with that of two indices, viz., Sensex and Nifty.

\section{Sampling design}

In this study, multi-stage purposive sampling method has been adopted to select the sample AMC's \& the schemes.

\section{Tools used for analysis}

The data pertaining to the NAVs and indices have been analysed to evaluate the performance of the sample schemes with the application of standard deviation and IRR.

\section{Limitations of the study}

This study considers only the top four AMCs from the public sector and the top six from the private sector and 
only a five year period, from April 2011 to March 2016 could be considered for this study, as a longer period adversely affects the number of available schemes with uniform data.

\section{Return and risk of the private and public sector mutual funds}

\section{Returns from sample schemes}

Investment in mutual funds by the investors is made with the expectation of earning more by exploiting the expertise of fund manager. This helps in evaluating the performance of the fund manager or the AMC's in the backdrop of the fund's objectives.

The notion behind this evaluation is to compare the returns obtained by the mutual fund scheme with the returns that would have been obtained by the investor had one or more alternative portfolios been chosen for investment. Such portfolios chosen for comparison are often referred to as 'benchmark portfolios'. Stock market index can be considered as one such benchmark.

To measure the returns, month-end NAVs of the selected sample schemes as announced by the asset management companies have been used. Though NAVs are available on daily basis, it has been proved that monthly NAVs make for more normal distribution. ${ }^{1}$ Evaluation can also be made on the basis of market prices. But, in the Indian context, the scrips of the mutual funds are very thinly traded and the secondary market for mutual fund units is rather weak. Hence, NAVs are considered as appropriate.

For each mutual fund scheme in the sample, the returns have been calculated taking month-end NAVs since April 2011 to March 2016. The NAVs are adjusted for dividends, by assuming that they are reinvested at the exdividend NAV. The returns are computed as:

$\mathrm{R}_{\mathrm{pt}}=\ln \left(\mathrm{NAV}_{\mathrm{t}} / \mathrm{NAV}_{\mathrm{t}-1}\right)$

where, $R_{p t}$ is the return of the scheme ' $p$ ' based on NAV in period ' $t$ ', where ' $t$ ' is the given month-end and ' $\mathrm{ln}$ ' is the natural logarithm to the base ' $\mathrm{e}$ '. The average return of the scheme is computed as follows:

$\mathrm{n}$

$\mathrm{AR}_{\mathrm{p}}=\sum \mathrm{R}_{\mathrm{t}=1} / \mathrm{n}$

where, $\mathrm{AR}_{\mathrm{p}}$ is the average return of the scheme and ' $\mathrm{n}$ ' is the total number of observations. ${ }^{2}$ The average returns of the selected sample schemes in the study period (April 2011 to March 2016) are tabulated in table 1.

Hence, out of the 53 public sector schemes, only 19 percent could give a yield of more than three percent, which is considerably less than that of the private sector schemes. Thus, comparatively, the returns from FoF and gilt schemes of the private sector are higher than that of the public sector schemes of the same category.

\section{Risk associated with sample schemes}

Performance of the mutual fund schemes cannot be evaluated in the isolation of return. The comparatively higher returns which are associated with mutual funds are blended with substantial degree of risk, which is the hallmark of the stock market.

Risk, with regard to investment, can be defined as the degree of probability of variations in the expected returns of the portfolios. This is considered as the basis of measuring or quantifying risk. Studies have mentioned that variability of returns measured in terms of standard deviation is the widely used measure of risk. Standard deviation is a statistical measure of dispersion of returns around average return.

Smaller the deviation smaller will be the spread of distribution and hence, lower will be the degree of risk. In this study, standard deviation (total risk) of the scheme's return is calculated for the entire sample of schemes. The total risk or standard deviation of returns is measured as:

$$
\underset{\mathbf{t}=1}{\sigma_{\mathrm{p}}}=1 / \mathbf{n}\left(\Sigma\left\{\mathbf{R}_{\mathbf{p t}}-\mathbf{A} \mathbf{R}_{\mathbf{p}}\right\}^{2}\right)^{1 / 2}
$$

where $\sigma_{\mathrm{p}}$ is the standard deviation of the sample scheme which indicates the scheme's total risk, $\mathrm{R}_{\mathrm{pt}}$ is the return over a period of time and $\mathrm{AR}_{\mathrm{p}}$ is the average return of the portfolio ' $p$ '. The calculated risk is classified into different classes and shown in table 2.

This underscores the fact that the private sector schemes come not only with higher return, but also with greater risk compared to the public sector schemes. This underscores the fact that there is significant difference in the total risk of the sample schemes that belong to the public sector and private sector. As noted earlier, the private sector schemes are riskier than the public sector schemes. 


\section{Testing of hypotheses}

This section presents testing of the hypotheses which have been framed in order to establish the performance of the sample schemes.

Null Hypothesis $\left(\mathrm{H}_{0}\right)$ : There is no significant difference in the risk between the public and private sectors' sample schemes.

Alternative Hypothesis $\left(\mathrm{H}_{1}\right)$ : There is significant difference in the risk between the public and private sectors' sample schemes.

This hypothesis is tested by taking total risk of the sample schemes as the testing variable and sector as the grouping variable and the test result is presented in table 3.

It is inferred from the result that the calculated t-value of 5.624 is statistically significant at 5 percent level and thus, the null hypothesis is rejected. This underscores the fact that there is significant difference in the total risk of the sample schemes that belong to the public sector and private sector. As noted earlier, the private sector schemes are riskier than the public sector schemes.

\section{Returns and risk of the sample schemes}

Here, the average returns of the sample schemes and their total risk are analysed combined. The overall returns and risk of the schemes are presented in table 4. The analysis of return and risk of the sample schemes indicates that comparatively, the returns from FoF and gilt schemes of the private sector are higher than that of the public sector schemes of the same category. More than half of the private sector schemes have less than four percent risk, which is mostly influenced by the income, ELS and gilt schemes.

The private sector schemes come not only with return, but also with higher risk compared to the public sector schemes. Also, higher return is unequivocally associated with greater risk. The beta of the sample schemes suggests that less number of schemes falls in the higher risk classes, when beta is analysed in terms of Nifty, than when the same is done in terms of Sensex.

This indicates that the sample schemes possess lesser degree of systematic risk in terms of Nifty, than under
Sensex. Also, typically, private sector schemes carry greater risk compared to the public sector schemes..

However, in the higher $\mathrm{R}^{2}$ ranges, the number of schemes is less under Nifty is quite less compared to the condition under Sensex. This section presents testing of the hypotheses which have been framed in order to establish the performance of the sample schemes.

Null Hypothesis $\left(\mathrm{H}_{0}\right)$ : There is no significant association between risk and returns of the sample schemes during the study period.

Alternative Hypothesis $\left(\mathrm{H}_{1}\right)$ : There is significant association between risk and returns of the sample schemes during the study period.

Return earned by the sample schemes are not independent of the risk associated with them. Higher return is always linked with higher risk as well. Among the different categories of schemes, those which provide greater return also carry greater risk.

This hypothesis is tested here with application of Pearson's Chi-square test by taking the average return and total risk of the sample schemes and the test result is presented in table 5. It is noted that the calculated Chisquare value of 14.725 is statistically significant at 1 percent level and thus, the null hypothesis is rejected.

The growth, balanced, FoF and ELS schemes which provide higher returns compared to the income, liquid and gilt schemes also carry greater risk and vice versa.

\section{Suggestions}

- Schemes such as growth, FoF and ELS provide higher return compared to income, liquid and gilt schemes, though the former are riskier than the latter.

- Risk-averters, obviously can invest in income, liquid and gilt schemes, while balanced schemes are as riskier as ELS schemes.

- The public sector schemes provide relatively less returns, but not without risk.

- Private sector schemes outperform the public sector schemes in all categories. 
Table.1 Sector-wise and category-wise average returns of the sample schemes, April 2011 to March 2016

\begin{tabular}{|c|c|c|c|c|c|c|c|}
\hline \multirow[b]{2}{*}{ Category } & \multicolumn{6}{|c|}{ Average Returns (in percentage) } & \multirow[b]{2}{*}{ Total } \\
\hline & $\begin{array}{l}\text { Below } \\
0.00\end{array}$ & $0.01-1.0$ & $1.01-2.0$ & $2.01-3.0$ & $3.01-5.0$ & $\begin{array}{l}\text { Above } \\
5.0\end{array}$ & \\
\hline \multicolumn{8}{|c|}{ Private } \\
\hline Income & Nil & 6 & 12 & 7 & Nil & Nil & 25 \\
\hline Balance & Nil & Nil & 3 & 4 & Nil & Nil & 7 \\
\hline Growth & 3 & 2 & 4 & 8 & 4 & 4 & 25 \\
\hline ELSS & Nil & Nil & 2 & 5 & Nil & Nil & 7 \\
\hline Liquid & Nil & Nil & 5 & 5 & 3 & Nil & 13 \\
\hline FoF & 2 & Nil & Nil & Nil & 6 & 2 & 10 \\
\hline Gilt & Nil & Nil & Nil & 3 & 4 & 3 & 10 \\
\hline All & 5 & 8 & 26 & 32 & 17 & 9 & 97 \\
\hline \multicolumn{8}{|c|}{ Public } \\
\hline Income & Nil & 3 & 7 & 4 & 1 & Nil & 15 \\
\hline Balance & Nil & Nil & Nil & 1 & 2 & 2 & 5 \\
\hline Growth & 3 & Nil & 2 & Nil & 3 & 2 & 10 \\
\hline ELSS & 2 & Nil & 2 & 2 & Nil & Nil & 6 \\
\hline Liquid & Nil & 4 & 3 & 1 & Nil & Nil & 8 \\
\hline FoF & 2 & Nil & Nil & 2 & Nil & Nil & 4 \\
\hline Gilt & Nil & 3 & 2 & 0 & Nil & Nil & 5 \\
\hline All & 7 & 10 & 16 & 10 & 6 & 4 & 53 \\
\hline
\end{tabular}

Source: AMFI

Table.2 Sector-wise and category-wise total risk of the sample schemes, April 2011 to March 2016

\begin{tabular}{|c|c|c|c|c|c|c|c|}
\hline \multirow[b]{2}{*}{ Category } & \multicolumn{6}{|c|}{ Total Risk (in percentage) } & \multirow[b]{2}{*}{ Total } \\
\hline & $\begin{array}{l}\text { Below } \\
2.0\end{array}$ & $2.01-3.0$ & $3.01-4.0$ & $4.01-6.0$ & $6.01-8.0$ & $\begin{array}{l}\text { Above } \\
8.0\end{array}$ & \\
\hline \multicolumn{8}{|c|}{ Private } \\
\hline Income & 4 & 5 & 11 & 5 & Nil & Nil & 25 \\
\hline Balance & Nil & Nil & 2 & 5 & Nil & Nil & 7 \\
\hline Growth & Nil & Nil & 7 & 5 & 8 & 5 & 25 \\
\hline ELSS & 2 & 3 & Nil & 2 & Nil & Nil & 7 \\
\hline Liquid & Nil & Nil & 10 & 3 & Nil & Nil & 13 \\
\hline FoF & Nil & Nil & 1 & 3 & 3 & 3 & 10 \\
\hline Gilt & Nil & 5 & 5 & Nil & Nil & Nil & 10 \\
\hline All & 6 & 13 & 36 & 23 & 11 & 8 & 97 \\
\hline \multicolumn{8}{|c|}{ Public } \\
\hline Income & 2 & 5 & 8 & Nil & Nil & Nil & 15 \\
\hline Balance & Nil & Nil & 2 & 2 & 1 & Nil & 5 \\
\hline Growth & Nil & Nil & Nil & 3 & 4 & 3 & 10 \\
\hline ELSS & Nil & 1 & 3 & 2 & Nil & Nil & 6 \\
\hline Liquid & 2 & 2 & 4 & Nil & Nil & Nil & 8 \\
\hline FoF & Nil & Nil & Nil & 4 & Nil & Nil & 4 \\
\hline Gilt & 2 & Nil & 3 & Nil & Nil & Nil & 5 \\
\hline All & 6 & 8 & 20 & 11 & 5 & 3 & 53 \\
\hline
\end{tabular}

Source: AMFI 
Table.3 Testing the difference in the total risk among the sample scheme

\begin{tabular}{|l|l|l|l|l|l|}
\hline \multirow{2}{*}{ Variable } & t-value & $\begin{array}{l}\text { Sig. } \\
(2-\text {-tailed })\end{array}$ & $\begin{array}{l}\text { Mean } \\
\text { Difference }\end{array}$ & \multicolumn{2}{|l|}{$\begin{array}{l}\text { 95\% Confidence Interval of the } \\
\text { Difference }\end{array}$} \\
\cline { 6 - 6 } & & & Lower & Upper \\
\hline Total Risk & $\mathbf{5 . 6 2 4} * *$ & $\mathbf{0 . 0 0 0}$ & $\mathbf{8 . 7 5 5}$ & $\mathbf{4 . 6 2 5}$ & 12.885 \\
\hline
\end{tabular}

Note: $* *$ indicates significance at 5 per cent level.

Source: Computed from field survey data.

Table.4 Returns and risk of the sample schemes, April 2011 to March 2016

\begin{tabular}{|l|c|c|c|c|c|c|c|}
\hline $\begin{array}{l}\text { Average } \\
\text { Return } \\
\text { (in \%) }\end{array}$ & \multicolumn{6}{|l|}{ Total Risk (in percentage) } & \multirow{2}{*}{ Total } \\
\cline { 2 - 7 } Below 0.0 & $\begin{array}{c}\text { Below } \\
2.0\end{array}$ & $2.01-3.0$ & $3.01-4.0$ & $4.01-6.0$ & $6.01-8.0$ & $\begin{array}{c}\text { Above } \\
8.0\end{array}$ & \\
\hline $0.01-1.0$ & 3 & 5 & 4 & Nil & Nil & Nil & 12 \\
\hline $1.01-2.0$ & 3 & 5 & 23 & Nil & Nil & Nil & 18 \\
\hline $2.01-3.0$ & Nil & 2 & 18 & 18 & Nil & Nil & 42 \\
\hline $3.01-5.0$ & Nil & Nil & 8 & 5 & 7 & Nil & 42 \\
\hline Above 5.0 & Nil & Nil & Nil & Nil & 5 & 8 & 23 \\
\hline All & 12 & 21 & 56 & 34 & 16 & 11 & 15 \\
\hline
\end{tabular}

Source: AMFI

Table.5 Testing the association between risk and returns of the sample schemes

\begin{tabular}{|l|c|c|c|}
\hline Particular & Value & df & Sig. (2-sided) \\
\hline Pearson Chi-Square & $14.725^{* * * *}$ & 1 & 0.000 \\
\hline Likelihood Ratio & 19.056 & 1 & 0.000 \\
\hline Linear-by-Linear Association & 21.339 & 1 & 0.000 \\
\hline N of Valid Cases & 150 & & \\
\hline
\end{tabular}

Note: $* * *$ indicates significance at 1 per cent level.

\begin{tabular}{|l|c|c|c|}
\hline Linear-by-Linear Association & 21.339 & 1 & 0.000 \\
\hline N of Valid Cases & 150 & & \\
\hline
\end{tabular}

Note: $* * *$ indicates significance at 1 per cent level.

Source: Computed from field survey data.

\section{Conclusion}

The analysis of the performance of the sample mutual funds indicates that most of the schemes fail to provide better risk-adjusted returns under both market indices, while sector-wise, underperformance is more among the public sector schemes. However, the degree of underperformance is less among the private sector schemes. Similarly, the risk quotient of the public sector schemes is also higher. In terms of diversification and stock selection too, most of the sample schemes fail to post additional return. The measure of market timing ability is the only excepThe analysis of return and risk of the sample schemes indicates that comparatively, the returns from $\mathrm{FoF}$ and gilt schemes of the private sector are higher than that of the public sector schemes of the same category. More than half of the private sector schemes have less than four percent risk, which is mostly influenced by the income, ELS and gilt schemes. The private sector schemes come not only with return, but also with higher risk compared to the public sector schemes. Also, higher return is unequivocally associated with greater risk.

The average return of the latter are less even in the higher risk classes, while in the case of private sector schemes, a greater proportion of schemes earn higher in the higher risk ranges. In both private sector and public 
sector, most of the growth schemes come under the umbrella of third and fourth groups. This shows the risky nature of the growth schemes. The beta of the sample schemes suggests that less number of schemes falls in the higher risk classes, when beta is analysed in terms of Nifty, than when the same is done in terms of Sensex. This indicates that the sample schemes possess lesser degree of systematic risk in terms of Nifty, than under Sensex. Also, typically, private sector schemes carry greater risk compared to the public sector schemes. Under Sensex, the degree of diversification of these public sector growth schemes is well spread out into all classes, though it is comparatively lower than the private sector growth schemes. Also, the growth schemes and the FoF schemes of the private sector are more diversified compared to the public sector. However, in the higher $\mathrm{R}^{2}$ ranges, the number of schemes is less under Nifty is quite less tion, where most of the schemes are able to generate not only positive but also statistically significant returns.

At the individual category level, growth schemes are the best performers under many of the measures and thus

\section{How to cite this article:}

Meenakshi, A. and Swaaminathan, Ti. M. 2017. An Inter-Temporal Analysis on the Performance of Select Mutual Funds in India. Int.J.Curr.Res.Aca.Rev. 5(3), 35-42. doi: https://doi.org/10.20546/ijcrar.2017.503.006 become the top five performers among the 150 sample schemes and all the five belong to the private sector. On the other, out of the five least performers, the bottom three belongs to the public sector. Hence, it can be concluded that during the study period, the private sector schemes performed better, of which the growth schemes are the best schemes.

\section{References}

Bansal, L.K. 1997. "Merchant Banking and Financial Services", Unistar Books, Chandigarh, pp. 6-8.

Fisher, Donald, E., and Jordan, Donald, J. 1995. "Security analysis and Portfolio Management", Prentice Hall, New Delhi, pp. 9-14.

Griffeth Bill. 1995. "The Mutual Fund Masters", Vision Books, New Delhi, pp. 22-29.

Khan, M.Y. 1980. "Indian Financial System", Vikas Publishing House, New Delhi, pp. 63-89.

Kuchhal, S.K. 1990. "Corporation Finance: Principles and Problems", Chaitanya Publishing House, Allahabad, pp. 358-371. 